\title{
UM OLHAR PARA AS RELAÇÕES ENTRE PLATONISMO E CONCEPÇÕES DE ENSINO DE MATEMÁTICA
}

\author{
FERNANDES, Fernando Luís Pereira ${ }^{1}$
}

\begin{abstract}
RESUMO: O presente texto foi produzido no âmbito de uma disciplina ofertada por um programa de pósgraduação em Educação no segundo semestre de 2015. Seu objetivo é, em um primeiro momento, apresentar brevemente um histórico sobre Platão e destacar os principais aspectos de sua Teoria das Ideias - a imortalidade da alma e a reminiscência. A segunda parte do texto estabelece relações entre o platonismo e concepções de ensino de Matemática. Notam-se elementos da concepção platônica de Matemática presentes nos cursos de formação inicial de professores, sendo que o ensino de Matemática sofreu influências dessa visão filosófica, como podemos perceber na semelhança entre o diálogo "Mênon" e uma típica aula tradicional de Matemática, além de artigos produzidos no campo da Educação Matemática.
\end{abstract}

Palavras-chave: Platonismo. Reminiscência. Concepção de Ensino de Matemática. Educação Matemática.

SUMMARY: This text was produced as part of course offered by a postgraduate studies program in Education in the second half of 2015. Its aim is, at first, to present briefly a history of Plato and highlight the main aspects of his Theory of Ideas - the immortality of the soul and the reminiscence. The second part of the text, to establish relationships between Platonism and Mathematics teaching conceptions. Are noticeable that platonic conception of Mathematics are present in the initial training courses for teachers and the teaching of mathematics was influenced this philosophical view, as we see the similarity between the dialogue "Mênon" and a typical traditional math class, and articles produced in the field of Mathematics Education.

Keywords: Platonism. Reminiscent. Mathematics Teaching Design. Mathematics Education.

\section{INTRODUÇÃO}

O presente texto é resultado de um trabalho acadêmico realizado no âmbito de uma disciplina de pós-graduação cursada no segundo semestre de 2015. A partir de diferentes concepções filosóficas estudadas durante o curso, optamos por realizar um breve ensaio acerca das possíveis relações entre o Platonismo, a Matemática e o seu ensino. Apesar de Platão não ter sido matemático, notamos o quanto suas ideias influenciaram a Grécia Antiga e a matemática produzida no período e os seus resquícios que ainda permanecem nos cursos de formação inicial de professores de Matemática.

O texto foi dividido em duas etapas. Na primeira, faremos um breve histórico da vida do filósofo grego, o contexto em que ele viveu em Atenas, apontando para as ideias principais deixadas por ele, como a reminiscência e o mundo das ideias. Na segunda etapa, destacaremos algumas produções da área de Educação Matemática que tratam das concepções de ensino de Matemática, buscando estabelecer relações entre essas concepções e a filosofia de Platão. Para finalizar, teceremos algumas considerações acerca dessas relações.

\footnotetext{
${ }^{1}$ Professor Assistente da Universidade Federal do Triângulo Mineiro (UFTM). Doutorando em Educação pela Universidade Federal de São Carlos (UFSCar).
} 


\section{Platão: breve histórico}

Segundo Marcondes (2007), Platão - que nasceu em Atenas no ano 428 a.C. e faleceu no ano 347 a.C. na mesma cidade - pertencia à aristocracia ateniense. Foi discípulo de Sócrates, de cujas ideias procurou constituir uma teoria para a filosofia, baseada na argumentação e no diálogo. Platão considerou Sócrates como personagem principal de boa parte de suas obras.

Sua visão de mundo trouxe avanços ao que Sócrates considerava ser a filosofia. Para Sócrates, a filosofia servia como reflexão, de modo que o indivíduo poderia ter uma melhor compreensão de si, em relação a valores e atitudes, através de uma auto reflexão ética. Já Platão considera a filosofia como uma teoria, na qual existiria uma metafísica, uma origem, uma essência para a natureza da realidade, colocando-a em condição de especulação e contemplação. Uma teoria que forneceria os subsídios para que se verificasse e distinguisse a verdade da opinião. É importante destacar que Platão não utiliza o termo metafísica, mas refere-se à busca pela "natureza essencial de algo" (MARCONDES, 2007, p.56). É possível que, a partir do caráter contemplativo e especulativo proposto por Platão, tenha se popularizado o termo platônico - como o amor platônico, por exemplo - que passou ao senso comum como sendo aquele que é inalcançável.

O contexto político no qual vivia Atenas foi um dos fatores que influenciaram sua filosofia. A cidade ateniense havia consolidado a sua democracia, mas não atendia ao verdadeiro significado dessa expressão, pois uma pequena parcela da população detinha o poder e se beneficiava daquilo que a cidade poderia oferecer de melhor. Em geral, os líderes eram aqueles que tinham recebido boa formação, possuíam boa oratória e eram oriundos da aristocracia, além de pequenos comerciantes.

É possível que a preocupação de Platão com a sua filosofia também tivesse papel político, uma vez que ele percebia a manutenção do status quo pelos aristocratas, embora ele mesmo fosse representante da aristocracia, mas que observava várias mudanças ocorrerem no funcionamento da cidadeestado. Para ele, a filosofia seria um caminho para combater os abusos e a falta de coerência daqueles que governavam Atenas.

\section{Platão e a Teoria das Ideias}

No diálogo "O Sofista” (PLATÃO, 2013a), fica evidente a crítica direta de Platão aos sofistas, ou seja, aqueles que ganhavam dinheiro a partir de argumentação constituída com base em crenças e opiniões. Os sofistas ensinavam a arte da retórica a jovens pertencentes à aristocracia, que tinham condições de pagar pelos serviços prestados e almejavam ingressar na política. Para Platão, tratava-se de má fé, pois, segundo ele, o que os sofistas faziam era iludir as pessoas e não instrui-las a partir de argumentos válidos. Era comum na cultura ateniense que um cidadão exercesse uma atividade sem a necessidade de obter um salário para tal. Entendemos ser esse mais um motivo para os sofistas não serem bem vistos pela sociedade da época.

Em um dos trechos do diálogo, há um debate entre o Estrangeiro de Eleia e o seu interlocutor, o jovem filósofo Teeteto, no qual aquele indaga ao jovem sobre a possibilidade de alguém como ele, humano, conhecer e saber falar sobre outros homens, animais, plantas e todo o universo que nos cerca. Para o Estrangeiro, o sofista não poderia conhecer tudo e todos, apesar de aparentar ser verdadeiro conhecedor (PLATÃO, 2013a, p-47-48). Ainda sobre "O Sofista", o Estrangeiro tece considerações sobre o filósofo e da dialética, afirmando que o filósofo é capaz de distinguir argumentos que sejam coerentes de outros, falaciosos, enquanto que os sofistas não teriam essa competência. 
No diálogo "Fédon", Platão explicita a imortalidade da alma a partir do julgamento de Sócrates. A morte era vista para a sociedade grega com terror, o fim de tudo e, para Platão, os sofistas se aproveitavam dessa crença para explorar e iludir as pessoas. Nas palavras de Sócrates, também personagem da obra, Platão destaca que o mundo material em que vivemos é, apenas, uma cópia mal feita de um mundo perfeito, para o qual retornaremos após vivermos encarnados, ou seja, ele demonstra a crença da imortalidade da alma. Um argumento utilizado por Sócrates para justificar é a ideia dos contrários. O grande viria do pequeno, o belo do feio, o quente viria do frio, e vice-versa. Assim, a vida viria da morte, e a morte da vida, em um ciclo permanente de busca da perfeição.

Outro aspecto presente em "Fédon", mas também presente no diálogo "Ménon", é a questão da reminiscência. Antes de nascermos, ou seja, reencarnarmos em um corpo, tivemos contato com as formas e as ideias perfeitas, presentes no Além. Ao encarnar, esquecemos-nos de tudo, sendo preciso relembrar aquilo que já conhecemos ao longo da vida. Assim, para Platão, a aprendizagem nada mais é do que um processo de recordar algo que já vimos e conhecemos. Ao recordar, entretanto, não conseguimos nos lembrar de ideias e formas perfeitamente, mas sim como cópia ou aparência do original. A maiêutica socrática (PLATÃO, 2013b) seria o processo que o filósofo utiliza para que um indivíduo possa relembrar do conhecimento aprendido antes de encarnar, possibilitando-o a seguir com a sua aprendizagem (ou recordação). Para alcançar a verdade, uma existência não seria suficiente, sendo, portanto, necessário fazer uso da razão, em detrimento da exploração dos sentidos.

É possível que a perspectiva racionalista tenha tido Platão como um de seus precursores (MARCONDES, 2007), tendo em vista o modo pelo qual sua filosofia foi constituída.

Sem dúvida, o platonismo impactou fortemente a cultura ocidental, em seus aspectos sociais e religiosos. O Catolicismo - ao considerar a imortalidade da alma - e a Doutrina Espírita - ao considerar o processo reencarnatório como chave para a evolução do espírito - são alguns exemplos de uma visão platônica no âmbito religioso. No que se refere à educação, em particular o ensino de matemática, percebe-se que também sofreu muitas influências do platonismo.

Sintetizando, a partir dos diferentes exemplos apresentados, podemos inferir que a filosofia de Platão, como teoria, pressupõe "ver, através de um processo de abstração e de superação de nossa experiência concreta, a verdadeira natureza das coisas em seu sentido eterno e imutável, de conhecer a verdade portanto". (MARCONDES, 2007, p.57)

\section{Platonismo e as concepções de ensino de Matemática}

Analisaremos agora as possíveis relações entre a concepção platônica e o ensino de matemática, destacando especialmente aspectos que caracterizam a Teoria das Ideias.

Em estudo realizado por Fiorentini (1995), o autor identifica seis tendências em Educação Matemática, consideradas como modelos de perceber e conceber o ensino de Matemática no Brasil e obtidas a partir de seis categorias descritivas: "a formalista clássica; a empírico-ativista; a formalista moderna; a tecnicista e suas variações; a construtivista e a socioetnoculturalista" (FIORENTINI, 1995, p.5).

A tendência sobre a qual nos debruçamos é a formalista-clássica, entendida como sendo a concepção platônica de ensino de matemática, compreendida pelo autor como aquela caracterizada

por uma visão estética, a-histórica e dogmática das ideias matemáticas como se essas existissem independentemente dos homens. Segundo essa concepção, a Matemática não é inventada ou construída pelo homem. O homem apenas pode, pela intuição e reminiscência, descobrir as ideias matemáticas que preexistem em um mundo ideal e que 
estão adormecidas em sua mente. (FIORENTINI, 1995, p.6)

Sob o ponto de vista didático, a aula era centrada no professor e em seu papel de transmitir o conteúdo, com base no livro texto, na memorização e repetição. Até os anos de 1950, os livros didáticos assumiam um formato do modelo euclidiano, nos quais eram apresentados os elementos primitivos e definições iniciais para que todo o conhecimento fosse sendo trazido aos poucos, sempre justificado pelas demonstrações. Denomina-se modelo euclidiano por seguir os moldes da obra de Euclides, matemático grego e autor de "Os Elementos", tratado de geometria composto por 13 livros, escrito por volta de 300 a.C., data posterior à morte de Platão. O modo de organização de "Os Elementos" tornou-se referência na organização da teoria matemática e, consequentemente, do ensino de geometria, numa perspectiva formalista e rigorosa até a primeira metade do século XX.

Podemos fazer uma analogia entre o diálogo de Sócrates com um escravo, presente no diálogo "Mênon", e uma aula expositiva de matemática. No diálogo, Sócrates faz demonstração de sua tese de que a reminiscência é uma característica do ser humano, que a aprendizagem deve ser por descoberta, tendo em vista que nós já a conhecemos de outras vidas e que, aos poucos, nos recordaremos daquilo com o que tivemos contato antes de retornarmos à vida corpórea.

Ele mostra que o escravo, não escolarizado, vai recordando - aos poucos - como construir um quadrado com o dobro da área do quadrado original.

Para nós, a relação presente no diálogo "Ménon" assemelha-se à de um professor na sala de aula, buscando ensinar determinado conteúdo matemático com base em um roteiro direcionado, de modo que o aluno relembre, aos poucos, tais conceitos. Sem dúvida, essa postura do professor, na grande maioria das vezes, não é consciente. É algo presente na cultura escolar, em especial nas aulas de matemática. Trata-se de um modelo de ensino com o qual tivemos contato desde os primeiros anos de escolaridade e, para aqueles que seguiram e seguem a graduação em Matemática, há uma identificação com essa concepção de matemática e seu ensino.

Esse círculo vicioso é reforçado na universidade. A formação do professor de Matemática, com relação aos conteúdos específicos da Matemática pura, é realizada por pesquisadores da área de matemática que, por sua vez, tiveram uma formação tal que reproduzem o método de ensino baseado no formalismo e rigor de linguagem, em uma aula expositiva.

Para Ciani, Ribeiro e Gonçalves Junior (2006), o problema estaria no modo de abordar os conteúdos de determinadas disciplinas no curso de Matemática. Em estudo realizado pelos autores, com base em questionários aplicados a estudantes egressos de um curso de Licenciatura em Matemática de uma universidade do estado do Paraná, visando identificar a compreensão e a importância de disciplinas de conteúdo específico de matemática para a sua formação, notaram que para boa parte dos egressos não percebia a relação entre o que se ensinou na graduação e o que se desenvolve na prática docente.

Isso vem ao encontro do que Moreira, Cury e Vianna (2005, p.21) tratam sobre a formação matemática do professor. Os autores entendem que a formação matemática do licenciando "submetida a um modelo de organização axiomática, utilizando uma linguagem formal, com os conceitos 'unificados' num alto grau de abstração e generalidade, etc" não são capazes de elucidar desafios e questões apresentados no cotidiano escolar. A nossa intenção não é generalizar e afirmar que todos os cursos de Licenciatura em Matemática tenham esse modelo de formação. Porém, como tivemos uma formação inicial nesses moldes e os autores supracitados apontam tais características na formação matemática do professor, entendemos que o modelo de formação inicial contribui significativamente para o exercício profissional do futuro professor da educação básica. 


\section{Algumas Considerações}

O breve estudo realizado e apresentado neste texto procurou destacar alguns dos aspectos mais importantes da concepção filosófica de Platão. A Teoria das Ideias, alicerçada na imortalidade da alma e a reminiscência, nos mostra uma perspectiva ideal de mundo, baseado em um caráter ético e político. Ético, pois seria com base no verdadeiro conhecimento que se poderia seguir no caminho do Bem (não de um Bem para o outro, mas de um Bem em si). Político, pois Platão visava atingir àqueles que detinham o poder de Atenas e que, segundo ele, manipulavam informações e promoviam a corrupção de maneira escancarada, fazendo uso da retórica e oratória para controlar a população.

Platão notava mudanças na cidade ateniense que, a nosso ver, o incomodavam por ele pertencer à aristocracia, e que o levariam a perder, em parte, a posição que ocupava. Afinal, a minoria aristocrática era quem tinha acesso à Academia e o poder econômico começava a abalar esse pilar de sustentação.

Em relação à concepção de ensino de Matemática, pudemos perceber o quanto ainda está presente a perspectiva filosófica de Platão, na formação inicial de professores de Matemática. Quando um professor ou um estudante consideram a Matemática como sendo estática, imutável, afirmando que o conhecimento é descoberto, e não uma construção humana, pode-se dizer que nesses pressupostos há elementos da concepção platônica de mundo. Em virtude da opção de modelo de formação matemática presente nos cursos de licenciatura, por meio da apresentação do conhecimento matemático como algo pronto e acabado, baseado no rigor e formalismo e expresso em linguagem matemática, parece-nos que essa perspectiva não tem contribuído para uma formação matemática que atenda às necessidades do professor de matemática da educação básica. Valeria, inclusive, um estudo mais detalhado nos atuais livros didáticos para saber se haveriam resquícios dessa concepção ainda em vigor na atualidade.

Como resultado desse estudo, podemos ressaltar a importância de estudar e conhecer diferentes concepções filosóficas, subsidiando a compreensão de teorias educacionais e concepções de ensino. No âmbito da disciplina de pós-graduação foi possível discutir, mesmo de maneira inicial, relações entre concepções filosóficas e projetos de pesquisa, desde os pré-socráticos até os filosófos contemporâneos. Notamos as influências do contexto histórico na constituição das diferentes filosofias, em geral se alternando entre o inatismo e o materialismo.

\section{REFERÊNCIAS}

CIANI, A. B.; RIBEIRO, D. M.; GONÇALVES JÚNIOR, M. A. Formação de Professores de Matemática: um Ponto de Vista de Egressos. In: Encontro Gaúcho de Educação Matemática, 9, 2006, Caxias do Sul. Anais... Caxias do Sul: Universidade de Caxias do Sul, 2006.

FIORENTINI, D. Alguns modos de ver e conceber o ensino de matemática no Brasil. Zetetiké, v. 3, nº 4, p.1-37, 1995.

MARCONDES, D. Iniciação à História da Filosofia: dos pré-socráticos a Wittgenstein. $15^{\text {a }}$ reimpressão. Rio de Janeiro: Zahar, 2007, 303 p.

MOREIRA, P. C. M.; CURY, H. N.; VIANNA, C. R. Por que análise real na licenciatura? Zetetiké, v.13, n.23, p.11-42, 2005.

PLATÃO. A Teoria das Ideias (tradução de Adalberto Roseira). São Paulo: Hunter Books, 2013a, 208 p.

PLATÃO. Apologia de Sócrates (tradução de Alexandre Romero). São Paulo Hunter Books, 2013b, 96p.

PLATÃO. Mênon. (trad. Maura Iglesias). Rio de Janeiro: Ed-PUC RIO; Loyola, 2001, 117 p. 
